\section{Patient advocacy: health, money or both?}

Dr. Bouzayen, in her recent editorial calling for public funding of in vitro fertilization (IVF), ${ }^{1}$ makes a convincing argument that the current high cost of IVF acts as an incentive for women to request multiple embryo transfers to increase their chance of pregnancy, despite the risk of multiple gestation and its associated complications. But why are their physicians performing these potentially hazardous procedures? It would appear these doctors are acting in a manner that is at least as "shortsighted" as those who do not support funding IVF. This article may have inadvertently highlighted a deeper concern than the funding: Are doctors capable of advocating for a patient's health in the setting of competing patient-related factors? At a minimum, Dr. Bouzayen seems to have shown that we need serious improvement in this area.

\section{Henry J. Conter}

Internal medicine resident

University of Alberta, Edmonton, Alta.

\section{REFERENCE}

1. Bouzayen R, Eggertson L. In vitro fertilization: A private matter becomes public. CMAJ 2009;181 243.

For the full letter, go to: www.cmaj.ca/cgi/eletters /181/5/243\#210888

DOI:10.1503/cmaj.109-2032

\section{Competing interests of authors}

I note that you have changed the threshold for determining whether the author has competing financial interests. ${ }^{1}$ I would agree that this has been a fairly arbitrary level. Having said that, I do not know what your level has been in the past. What I would like to suggest is that you simply ask the authors to declare how much money in total they have received from all particular companies over the last five year period. If this material is presented to the readers, the readers would be in the position to make their own decision as to whether there was a conflict of interest. If someone has received $\$ 3000$ from a company, to my way of thinking it is much different than if they received several million dollars over five years. In the latter case, I would be prepared to believe that the physician may be seriously influenced by that level of income. It is my view that it would be a regressive step to abandon thresholds and I would urge you to go for total transparency, which would allow readers to make up their own minds on these matters.

\section{Derryck H. Smith}

Clinical professor, Department of Psychiatry, University of British Columbia,

Vancouver, BC

\section{REFERENCE}

1. Stanbrook MB, Flegel K, MacDonald N, et al Competing interests of authors: We have revised our policy. CMAJ 2009;181:11-12.

For the full letter, go to: www.cmaj.ca/cgi/eletters /181/1-2/11\#215069

DOI:10.1503/cmaj.109-2033

\section{Primary care and type 2 diabetes mellitus}

Re: "Controlling the complications of diabetes: It's about the sugar." The controversy regarding glycemic control is further than ever from resolution. Type 2 diabetes mellitus (T2DM) is a common and growing primary care disease that attracts strong attention from the pharmaceutical industry. While management of T2DM, including diagnosis, treatment, monitoring, lifestyle and long-term patient-doctor relationship, is a primary care field, official guidelines originate from specialists and diabetologists without benefit of a strong primary care perspective. We in the field have repeatedly seen study results interpreted to support more interventions. The research use of rela- tive risk, surrogate and composite endpoints does little to engender faith at the coal face of medicine. The hallmark of good primary care of a T2DM patient comes with understanding the care of the whole patient. Many of our patients are poor, uneducated, obese and suffer from multiple comorbidities. We must accept them as and where they are, moving forward at their pace. This means we need to keep it simple. Metformin and NPH (neutral protamine Hagedorn) insulin adjusted on 3 monthly A1c measurements is doable for most patients. On the other hand, frequent home glucose monitoring, highly advertised by a variety of entertainers at the behest of for-profit companies, is not supported by evidence. Most patients may be better served by discussing a different set of numbers: how many cigarettes they still smoke, the number of minutes of walking or exercise they achieve, how affordable their medications are. As things stand today, with the advertising being married to the clinical practice guidelines, those patients with T2DM who do not frequently measure their blood glucose are made to feel irresponsible at best, despite any evidence to support this. In the long term, this will work against the best interests of many patients.

\section{Len Kelly MD}

Sioux Lookout, Ont.

Keith MacLellan MD

Shawville, Que.

\section{REFERENCE}

1. Flegel K. Controlling the complications of diabetes: It's about the sugar. CMAJ 2009;181:357.

For the full letter, go to: www.cmaj.ca/cgi/eletters /181/6-7/357\#206053

DOI:10.1503/cmaj.109-2037

\section{Euthanasia debate reignited}

It is notable that after all the years of discussions that followed the Sue Rodriguez case, we are still insinuating that "pain so intense" (which painkillers do not alleviate) leads near-death 